\title{
Nutritional Psychiatry: Connecting Depression and Heart Failure with The Science of Nutrition
}

\author{
Thais de R Bessa- Guerra ${ }^{1,23 *}$, Adalgiza Mafra Moreno², Mauto Victor Mendlowicz ${ }^{3}$, Evandro T \\ Mesquita $^{3}$ \\ ${ }^{1}$ Scientific Department, Brain and Heart Nutrition Institute (INCCOR). Brazil \\ ${ }^{2}$ Faculty of Medicine; Graduate Program, Iguaçu University (UNIG), Brazil, Rio de Janeiro \\ ${ }^{3}$ Faculty of Medicine, Postgraduate Program in Cardiovascular Sciences, Universidade Federal Fluminense (UFF), Brazil, Rio de Janeiro. \\ Brazil \\ *Corresponding author: Thais de Rezende Bessa Guerra, Scientific Department, Brain and Heart Nutrition Institute (INCCOR). \\ Brazil
}

\section{ARTICLE INFO}

Received: 慧 October 28, 2020

Published:

Citation: Thais de R Bessa- Guerra, Adalgiza Mafra Moreno, Mauto Victor Mendlowicz, Evandro T Mesquita. Nutritional Psychiatry: Connecting Depression and Heart Failure with The Science of Nutrition. Biomed J Sci \& Tech Res 31(4)-2020. BJSTR. MS.ID.005138.

\begin{abstract}
Nutritional Psychiatry is a term used to describe a field of research, and a way of approaching the prevention and treatment of mental illness, which focuses on diet and nutrition. Among the complexity of the determinants of Mental Health problems, the emerging evidence from Nutrition shows relevant factors in the high prevalence of mental disorders, suggesting that diet is as important for Psychiatry as for Cardiology, Endocrinology and Gastroenterology. Studies of the relationship between diet quality (and potential nutritional deficiencies) and mental health disorders, as well as the use of nutrients to treat deficiencies, are increasing. Nutritional psychiatry has been promoting the interaction between the cardiologist-nutricionist-neurocientist, which has been recommended in the nutritional care of patients with chronic diseases, among them: heart failure. Certainly, this new area of nutritional psychiatry will allow us to broaden our look under the conception of future research that evaluates intervention in psychiatrynutrition-cardiology a multidisciplinary and interdisciplinary approach.
\end{abstract}

Keywords: Nutritional Psychiatry; Depression, Heart failure; Nutrition

\section{What's the Evidence?}

Nutritionalpsychiatryis anewareafor thestudy of the correlation of mental disorders, metabolic abnormalities, nutrition in chronic diseases [1]. The term "Nutritional Psychiatry" emerged in 2013 after a consensus statement that advocated as a new field of research focused on the comprehensive development of evidence, cohesive and scientifically rigorous to support a shift in thinking around the role of diet and nutrition in health [2]. Nutritional psychiatry has been promoting the interaction between cardiologist-nutricionistpsychiatrist-neurocientist, which has been recommended in the nutritional care of patients with chronic diseases, among them: heart failure [1-3]. HF is a complex clinical syndrome, often chronic in nature, which is associated with metabolic, inflammatory, nutritional abnormalities and has a high prevalence of depression $[1,4]$. HF promotes metabolic and nutritional abnormalities that are associated with different multimorbidities, among them depression. Current evidence shows that better food quality, i.e. fruits, vegetables, fish and whole grains are associated with lower risk for depressive symptoms, but not all available results are consistent with the hypothesis that diet influences the risk to develop depression $[3,5,6]$. Depression when associated with heart conditions causes inflammatory, metabolic and nutritional disorders. Lifestyle and particularly nutrition seem to be able to influence the development and course of depressive morbidity. Different nutrients or different dietary patterns can influence the aggravation of depressive symptoms, but are not yet explored in $\mathrm{HF}$ $[1,2,7]$.

Nutritional aspects are so important in mental health that they have inspired researchers to a new field of multidisciplinary research called nutritional psychiatry. The inter and multidisciplinary approach involving nutritionists, nutrologists, psychiatrists, 
psychologists, neuroscientists and cardiologists specializing in HF has allowed a transdisciplinary look at the relationship in mind/ brain and metabolism, lifestyle and nutrition in chronic diseases [7]. The changes in the dietary pattern have been reported with the worsening of depressive symptoms and depression, resulting in increased inflammation and oxidative stress, consequently in nutritional deficiencies and depletion of essential fatty acids. Nutrients form the substrate of essential biological processes in the body and brain, thus ensuring that nutrient levels are adequate in patients suffering from serious diseases is important $[1,8]$. In the study conducted by Sarris et al., [3] in the area of nutritional psychiatry showed that patients who consumed foods rich in omega 3 or eicosapentaenoic acid (EPA) showed strong association in significantly reducing depressive symptoms. In addition, other studies alone showed that the benefits of creatine supplementation by adding zinc, vitamin $\mathrm{C}$, the amino acid tryptophan and folic acid produced mixed results in depressed patients, however, considered all these supplements relatively safe.

Although, it is not the focus of nutritional psychiatry to support the use of nutritional supplements. Jacka et al. 2017 have speculated that the use of these supplements can increase the effectiveness of antidepressants in various ways, perhaps directly altering the activity of neurotransmitters or indirectly, reducing inflammation, known to contribute to depression. However, research in this area is gradually uncovering potential facts based on their specific nutritional deficiencies, brain conditions and genetic profiles, seeking to understand the basic factors that can influence nutrient metabolism, including intestinal health [1-5]

\section{What Is the Connection?}

Another important aspect in this connection of the nutritional state - depression - CI is obesity. Obesity increases the chance by four times the risk of developing depression. In patients with $\mathrm{HF}$, obesity is related to several alterations in cardiac structures, cardiac hypertrophy, increase in epicardial fat and infiltration of myocardial fat, enlargement of the right ventricle cavity and alteration in the left ventricle ejection fraction (LVEF). Despite this, obesity has also been identified as a protective factor for the risk of mortality from $\mathrm{HF}$, a factor referred to in the literature as "reverse epidemiology". A hypothesis for reverse epidemiology would be the fact that HF itself generates catabolic state in the individual. Thus, obese individuals with a higher metabolic reserve are resistant to catabolic condition [6-9]. However, there is little evidence of studies associated with depression and nutritional changes in patients with HF. In this sense, in figure 1 connecting the concepts of HF with the evidence of nutritional psychiatry - to generate knowledge about nutritional factors and design studies directed and personalized to depression and other psychiatric diseases in order to promote quality of life and survival in these patients [10]. Currently, we have started in Brazil the pioneering research in the line of nutritional psychiatry in patients with heart failure, which is an innovation in the field of research, because in this study we think about mental and brain health and the relationship with cardiology, the model focused on integrative physiology, nutritional aspects and the understanding of biomarkers.

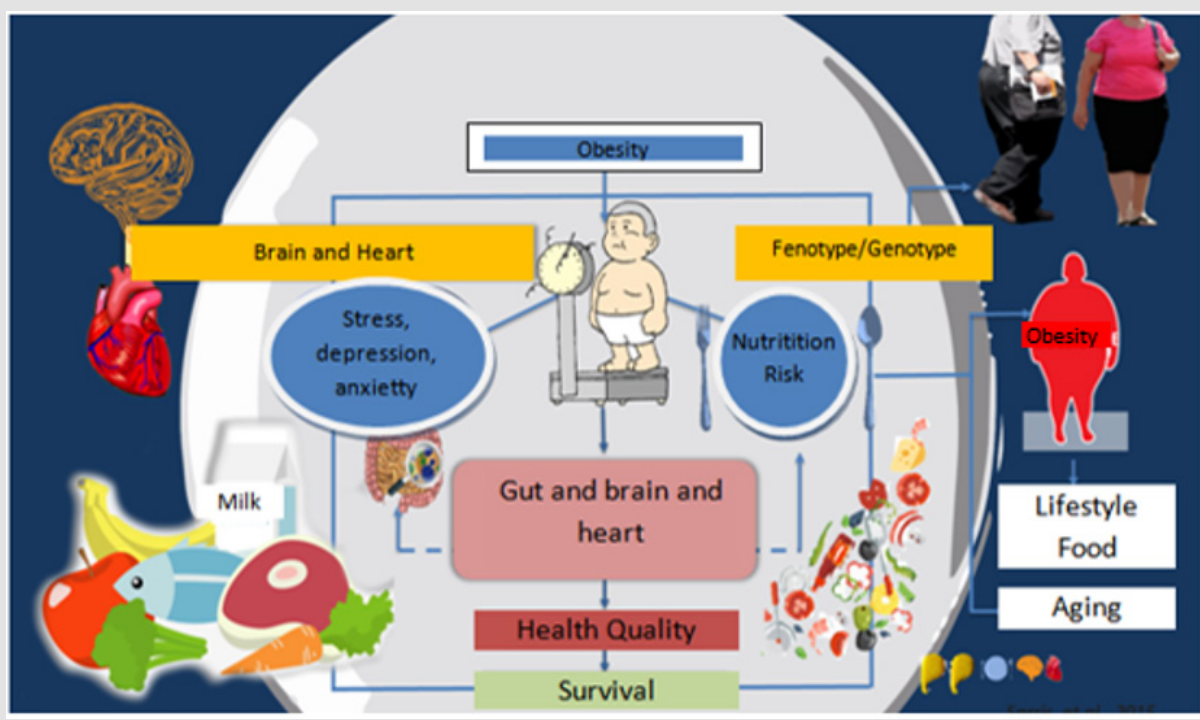

Figure 1: Nutritional psychiatry: Depression-heart insufficiency-nutrition connection (10).

Certainly, this new area of nutritional psychiatry will allow us to broaden our look under the design of future research that evaluates the intervention in mental health - nutrition - cardiology - facing a multi and interdisciplinary approach.

\section{References}

1. FN Jacka (2017) Nutritional Psychiatry: Where to Next? EBioMedicine. 17: 24-29.

2. W Marx, G Moseley, M Berk, Felice Jacka (2017) Nutritional psychiatry: The present state of the evidence. Proceedings of the Nutrition Society 76: 4: 427-436. 
3. Jacka FN, O Neil A, Opie R, Itsiopoulos C, Cotton S, et al. (2017) A randomised controlled trial of dietary improvement for adults with major depression (the 'SMILES' trial). BMC Med 15:23.

4. Baxter AJ, Patton G, Scott KM, Degenhardt L, Whiteford HA, et al. (2013) Global epidemiology of mental disorders: what are we missing? PLoS One 8(6): e65514.

5. (2018) Coordinating Committee for the Heart Failure Directive. Brazilian Guideline for Chronic and Acute Heart Failure. Arq Bras Cardiol. 111(3): 436-539.

6. RB Othman, O Mziou, A Gamoudi, Amal Smida, Cyrin Souissi, et al. (2018) Nutritional Status of Depressive Patients. J Diabetes Metab 9: 2.

\section{ISSN: 2574-1241}

DOI: 10.26717/BJSTR.2020.31.005138

Thais de R Bessa- Guerra. Biomed J Sci \& Tech Res

(C) This work is licensed under Creative

Submission Link: https://biomedres.us/submit-manuscript.php
7. JJ McMurray, S Adamopoulos, SD Anker (2016) The Task Force for the Diagnosis and Treatment of Acute and Chronic Heart Failure of the European Society of Cardiology. Eur Heart J 33(14): 1787-847.

8. E Zamora, C Díez-López, J Lupón, Marta de Antonio, Mar Domingo, et al. (2016) Weight Loss in Obese Patients with Heart Failure. J Am Heart Assoc 24(3): 5 .

9. JMP RUIZ (2017) Impact of nutritional assessment in patients with heart failure. Nutr Hosp. 34(6): 1265-1266.

10. Guerra B by R Thais (2018) The nutritional psychiatric paradigm associated with different methods of depression in patients with heart failure. PhD Thesis in Cardiovascular Sciences; Universidade Federal Fuminense)

$\begin{array}{ll}\text { BIOMEDICAL } & \text { Assets of Publishing with us } \\ \text { RESEARCHES } & \text { - Global archiving of articles } \\ & \text { - Immediate, unrestricted online access } \\ & \text { - Rigorous Peer Review Process } \\ & \text { - Authors Retain Copyrights } \\ \end{array}$

